\title{
Thermal tolerance in a south-east African population of the tsetse fly Glossina pallidipes (Diptera, Glossinidae): Implications for forecasting climate change impacts
}

\author{
John S. Terblanche*, Susana Clusella-Trullas, Jacques A. Deere, Steven L. Chown \\ Centre for Invasion Biology, Department of Botany and Zoology, Stellenbosch University, Private Bag X1, Matieland 7602, South Africa
}

Received 27 June 2007; received in revised form 11 August 2007; accepted 14 August 2007

\begin{abstract}
For tsetse (Glossina spp.), the vectors of human and animal trypanosomiases, the physiological mechanisms linking variation in population dynamics with changing weather conditions have not been well established. Here, we investigate high- and low-temperature tolerance in terms of activity limits and survival in a natural population of adult Glossina pallidipes from eastern Zambia. Due to increased interest in chilling flies for handling and aerial dispersal in sterile insect technique control and eradication programmes, we also provide further detailed investigation of low-temperature responses. In wild-caught $G$. pallidipes, the probability of survival for $50 \%$ of the population at low-temperatures was at $3.7,8.9$ and $9.6^{\circ} \mathrm{C}\left(95 \%\right.$ CIs: $\left.\pm 1.5^{\circ} \mathrm{C}\right)$ for 1,2 and $3 \mathrm{~h}$ treatments, respectively. At high temperatures, it was estimated that treatments at $37.9,36.2$ and $35.6{ }^{\circ} \mathrm{C}\left(95 \%\right.$ CIs: $\left.\pm 0.5^{\circ} \mathrm{C}\right)$ would yield $50 \%$ population survival for 1,2 and $3 \mathrm{~h}$, respectively. Significant effects of time and temperature were detected at both temperature extremes (GLZ, $p<0.05$ in all cases) although a time-temperature interaction was only detected at high temperatures $(p<0.0001)$. We synthesized data from four other Kenyan populations and found that upper critical thermal limits showed little variation among populations and laboratory treatments (range: $43.9-45.0^{\circ} \mathrm{C} ; 0.25^{\circ} \mathrm{C} / \mathrm{min}$ heating rate), although reduction to more ecologically relevant heating rates $\left(0.06^{\circ} \mathrm{C} / \mathrm{min}\right) \mathrm{reduce}$ these values significantly from $\sim 44.4$ to $40.6^{\circ} \mathrm{C}$, thereby providing a causal explanation for why tsetse distribution may be high-temperature limited. By contrast, low-temperature limits showed substantial variation among populations and acclimation treatments (range: $\left.4.5-13.8^{\circ} \mathrm{C} ; 0.25^{\circ} \mathrm{C} / \mathrm{min}\right)$, indicating high levels of inter-population variability. Ecologically relevant cooling rates $\left(0.06{ }^{\circ} \mathrm{C} / \mathrm{min}\right)$ suggest tsetses are likely to experience chill coma temperatures under natural conditions $\left(\sim 20-21^{\circ} \mathrm{C}\right)$. The results from acute hardening experiments in the Zambian population demonstrate limited ability to improve low-temperature tolerance over short (hourly) timescales after non-lethal pre-treatments. In flies which survived chilling, recovery times were non-linear with plateaus between $2-6$ and $8-12{ }^{\circ} \mathrm{C}$. Survival times ranged between 4 and $36 \mathrm{~h}$ and did not vary between flies which had undergone chill coma by comparison with flies which had not, even after factoring body condition into the analyses ( $p>0.5$ in all cases). However, flies with low chill coma values had the highest body water and fat content, indicating that when energy reserves are depleted, low-temperature tolerance may be compromised. Overall, these results suggest that physiological mechanisms may provide insight into tsetse population dynamics, hence distribution and abundance, and support a general prediction for reduced geographic distribution under future climate warming scenarios.
\end{abstract}

(C) 2007 Elsevier Ltd. All rights reserved.

Keywords: Seasonal variation; Phenotypic plasticity; Fitness costs; Cold tolerance; Geographic distribution; Trade-offs; Climate change; Insect vector

\section{Introduction}

Recent demonstrations and predictions of the biological effects of anthropogenic climate change have revived interest in the factors determining the abundance and

\footnotetext{
*Corresponding author. Tel.: + 2721808 2385; fax: + 27218082405 .

E-mail address: jst@sun.ac.za (J.S. Terblanche).
}

distribution of plants and animals (Walther et al., 2002; Thomas et al., 2004; Thuiller et al., 2005; Wilson et al., 2005; Kerr et al., 2007). Among the organisms in which range shifts have already been documented (Parmesan and Yohe, 2003) and are predicted to continue (Helmuth et al., 2002; Roura-Pascual et al., 2004; Kearney and Porter, 2004; Urban et al., 2007), disease vectors are of considerable significance given their roles in compromising human 
and veterinary health, and in consequence, regional economic development (Patz et al., 2000; Patz, 2002; Harvell et al., 2002; Rogers et al., 2002; Sutherst, 2004; Pascual et al., 2006). Much theoretical and empirical work has been undertaken on the likely effects of climate change on disease vectors (Martens et al., 1999; Githeko et al., 2000; Bourne et al., 2001; Kovats et al., 2001; Rogers and Randolph, 2006), demonstrating that substantial differences in climate change responses exist among vectors, and therefore the diseases they transmit (Hulme, 1996; Martens et al., 1999). For example, climate change has been strongly associated with increasing risk of transmission of bluetongue virus (Kuhn et al., 2003; Purse et al., 2005) but not for that of malaria (Rogers and Randolph, 2000) or tickborne encephalitis (Sumilo et al., 2007).

In the case of tsetse-born trypanosomiasis, declared recently an under-investigated vector-borne disease (Cattand et al., 2006), few predictions have been made concerning likely climate change effects. Rogers and Packer (1993) suggested that in East Africa, climate change would result in an increase in available habitat and thus a possible expansion of the overall range of tsetse, particularly into high-altitude areas that may currently exclude the species owing to low temperatures (see also Rogers and Randolph, 1993). By contrast, other reports have suggested a net decline in the distributional range of the tsetse species considered. For example, under various future climate change scenarios Glossina morsitans is expected to experience a reduction in suitable habitat and hence a contraction of its geographic range (Hulme, 1996). Further confounding the issue is the related question of whether autonomous control will effectively render tsetse-borne trypanosomiasis an increasingly unimportant problem (Bourne et al., 2001; see also Rogers and Randolph, 2002). Nonetheless, it might be predicted that changes in temperature and moisture regimes would have a substantial influence on the abundances and distributions of tsetse owing to the strong relationships between these population-level characteristics and the environmental variables.

Many studies have demonstrated strong relationships between temperature and moisture availability, and the abundance and/or distribution of Glossina spp. at both coarse and fine scales. For example, spatial distribution data collected for regions such as south-central Africa show strong relationships with these environmental variables (e.g., Robinson et al., 1997a, b; Rogers and Robinson, 2004), as does distribution and abundance data recorded across the continent (Rogers and Williams, 1994; Rogers, 2000; Rogers and Robinson, 2004). In the case of G. morsitans, suitable habitat, as indicated by fly presence or absence, is marked by a temperature difference of only $0.5^{\circ} \mathrm{C}$ for the sub-species in south-central Africa (Robinson et al., 1997a, b). Likewise, at both short and long time scales, fly abundance is positively related to temperature and humidity (Kitron et al., 1996; MohamedAhmed and Wynholds, 1997; see also Huyton and Brady, 1975; Van Etten, 1982; Rogers and Randolph, 1991; Esterhuizen et al., 2005). Indeed, tsetse demographics are strongly influenced in all life stages by temperature, and by moisture availability (Bursell, 1959; Langley, 1977; Rogers, 1990; Hargrove, 2001, 2004), although the functions describing these relationships can differ markedly within and between various life stages. For example, increasing mean monthly maximum temperature in the range of $25-36^{\circ} \mathrm{C}$ is correlated with a linear reduction in weekly survival probability, especially in Glossina morsitans morsitans (Hargrove, 2001), and declining water availability may have a similar influence (Rogers and Randolph, 1986; Hargrove, 2004).

Despite these obvious links between environmental variables, demographic change, and estimates of field abundance and distribution, it is not yet clear what the mechanistic basis is thereof. For example, the negative relationship between increasing temperature and survival probability might reflect direct physiological temperature sensitivity, an indirect physiological effect mediated through increasing metabolic rates requiring more frequent feeding and therefore higher foraging risk (Torr and Hargrove, 1999; Hargrove, 2004; Terblanche and Chown, 2007), or simply an increase in predation owing to greater activities of other species (see Leak, 1999). Each of these mechanisms has very different implications for models of the impacts of climate change on tsetse abundance and distribution. The first suggests that reasonably straightforward climatic envelope models (see Hijmans and Graham, 2006) might be extrapolated to future conditions, whilst the latter two mechanisms indicate that matters may be substantially more complicated. In consequence, mechanistic understanding of the likely links between the abiotic environment and the dynamics of a population is required to develop realistic climate envelope models, particularly those which use physiological information to define limits or critical thresholds to animal function and performance (Helmuth et al., 2005). Indeed, such a mechanistic approach can provide major insights into the likely effects of climate change on species distributions and abundance (see Kearney and Porter, 2004; Pörtner and Knust, 2007), because it presents an alternative to the more correlative climate-matching approaches typically used to make such forecasts (e.g., Rogers et al. (2002), Rogers and Robinson (2004), Sumilo et al. (2007); for recent reviews of climate modelling methods, see Graham and Hijmans, 2006; Rogers, 2006). Thus, in the first part of this study we examine the direct responses of an important south-east African vector of trypanosomiasis, Glossina pallidipes, to high and low temperature, to determine whether these responses might constitute an important link between temperature, population dynamics and geographic distributions (see Gaston (2003) for general review of this field).

In the second part of the study, we examine the short-term responses of this species to low temperatures. Early work suggested that low-temperature developmental constraints probably set the low-temperature limits to tsetse distribution (e.g., Bursell, 1960; Phelps and Burrows, 1969). In consequence, the low-temperature physiology of adult tsetse is typically not well studied (exceptions include early work by 
Mellanby (1936), Burnett (1957), Phelps and Burrows (1969); reviewed in Bursell (1964)). Also, thermal limits to activity have not been well explored in tsetse (but see, for example, Macfie, 1912; Mellanby, 1936), and lower lethal limit data are restricted to a few species only. Moreover, interest in the lowtemperature physiology of tsetse is increasing because of the ongoing, though controversial (see Rogers and Randolph, 2002) proposals for the use of sterile insect technique (SIT) for their control and eradication. Indeed, flies reared for SIT are typically chilled for handling and sorting prior to and during aerial dispersal (Burnett, 1957; Leak, 1999), and chilling is regularly used for sorting flies in the laboratory. Much interest therefore exists in understanding how lowtemperature treatments may influence fly performance (e.g. Mutika et al., 2001) and survival. For example, a rapid cold hardening response, as has been found in other fly taxa (Lee et al., 1987; Nilson et al., 2006), could result in flies recovering during handling and transport, which in turn could negatively affect the efficacy of laboratory work and SIT programmes. Moreover, broad divergence in physiology between laboratory colonies and field populations (Terblanche et al., 2006) raises issues of mating compatibility and the competitiveness of colony-bred flies released into wild populations.

Therefore we (i) investigate acute time $\times$ temperature effects on adult survival and limits to activity, (ii) synthesize available information and explore sources of intraspecific variation in thermal tolerances in G. pallidipes (e.g., geographic variation, acclimation, experimental methodology), (iii) determine if this species has the capacity to rapidly cold harden (reviewed in Chown and Nicolson (2004), Terblanche et al. (2007)) after pre-exposure to sublethal temperatures, (iv) explore the effects of temperature on chill coma recovery time and (v) examine short-term costs associated with chill coma and assess the possibility that energy metabolism plays a role in cold tolerance.

\section{Methods and materials}

\subsection{Study sites and collection}

The work focuses on adult flies because they are the life stage most susceptible to high-temperature effects in the wild (Hargrove, 2004), and because adult flies are those that will be released in SIT operations (Leak, 1999). Field- collected G. pallidipes (Diptera: Glossinidae) were trapped in the South Luangwa National Park, Zambia (Mfuwe, Table 1). For each of the field experiments, flies were collected from 10 odour-baited Ngu traps (key attractive components: 4-methyl-phenol, 3-n-propynol, and acetone) spread over several kilometres near the park entrance. Following removal from the traps, the flies were transported in an insulated container to the field laboratory situated $<2 \mathrm{~h}$ away. At the laboratory, flies were randomly separated into groups for each of the experimental procedures after which experiments commenced immediately. All experimental work took place over a 3-week period in October 2006 prior to the start of the rainy season. For some measures of thermal tolerance, data from a previous study (Terblanche et al., 2006) were used to document thoroughly intra-specific variation (see Table 1 for geographic and climate details of all populations included in this analysis).

\subsection{Lethal temperatures}

Instead of attempting to age flies in the field by wing-fray techniques, we assumed that age, gender and feeding status effects were relatively small for temperature tolerance estimates. Preliminary laboratory experiments for critical thermal limits suggested that this is the case for G. pallidipes (see detailed appendix in Terblanche et al., submitted for publication; Terblanche et al., 2006). Lethal temperature limits were assessed using a 'plunge' protocol (as in, for example, Sinclair et al., 2006). Active flies were selected for experiments while flies with flattened or foldedover abdomens which indicate severe starvation and could potentially influence stress resistance were deliberately excluded. Flies were sorted into groups and loaded into $60 \mathrm{ml}$ polypropylene vials $(n=8-12$ individuals per vial). Each temperature treatment was repeated at three different durations: 1, 2 and $3 \mathrm{~h}$. A minimum of five replicated vials was used per temperature/time treatment. Low-temperature treatments covered the range $0-18{ }^{\circ} \mathrm{C}$ while hightemperature treatments included $30-44^{\circ} \mathrm{C}$. During lethal temperature experiments, relative humidity (r.h.) was controlled to $\sim 76 \%$ using saturated $\mathrm{NaCl}$ solutions within each vial. A piece of plastic mesh ensured that flies did not come into direct contact with the salt solution. After water

Table 1

Geographic co-ordinates, mean annual temperature (MAT), mean monthly temperature range (MMTR), mean annual rainfall (MAR) and altitude for sampling locations used to estimate inter-population physiological variability in Glossina pallidipes

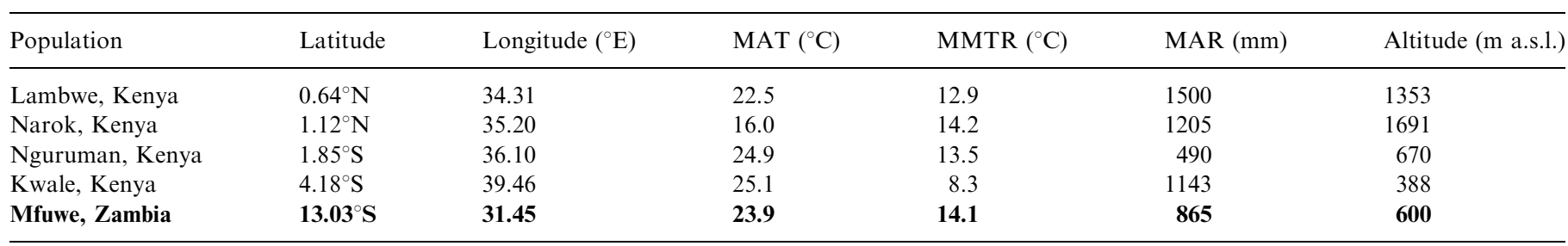

Climate data obtained from DIVA-GIS software (see Hijmans et al. (2005) for details on interpolation and averaging). Physiological data for the Kenyan populations were reported in a previous study (Terblanche et al., 2006). Data from the present study is given in bold font. 
bath temperatures had been verified with mercury thermometers, flies held in non-airtight vials placed within watertight plastic bags were submerged in water baths for each treatment. Upon completion of a temperature treatment, vials were transferred to a Peltier-controlled temperature cabinet (PTC-1, Sable Systems, Las Vegas, $\mathrm{NV}$, USA) for $4 \mathrm{~h}$ at $30^{\circ} \mathrm{C}$ before survival was scored. The use of field-collected flies precluded survival assessments after longer periods because we sought to eliminate the confounding effects of starvation (attempts made to feed flies using the membrane tray system typically used for feeding laboratory-reared flies were unsuccessful likely owing to learned feeding behaviour (Bouyer et al., 2007)). Survival was considered co-ordinated behaviour (such as flight or walking) or a co-ordinated response to mild stimulus (prodding). Analyses were performed to investigate the effects of time, temperature and the interactions thereof on survival, using generalized linear models in SAS v. 9.0 (SAS Institute, Cary, NC, USA), assuming a binomial distribution and a logit link function with deviance scaled to 1 to correct for overdispersion (results presented in Table 2).

\subsection{Critical thermal limits}

Preliminary laboratory work and field investigations (Terblanche et al., 2006) have shown that these traits are reliable and repeatable indicators of thermal tolerance within populations over time (and reviewed in Chown and Nicolson (2004)). To enable comparisons with a previous study of populations of this species from East Africa (Terblanche et al., 2006), critical thermal limits were assessed using that study's methods. In brief, a programmable water bath (LTC-12, Grant Instruments, UK) was used to regulate the temperature of water flowing through an insulated double-jacketed series of chambers ('organ pipes'). Flies placed individually into these chambers were subjected to heating or cooling at constant rates $\left(0.25^{\circ} \mathrm{C} / \mathrm{min}\right)$ and the temperature at which critical thermal limits occurred was recorded. The point of critical thermal minimum $\left(\mathrm{CT}_{\mathrm{Min}}\right)$ was defined as the loss of co-ordinated muscle function, and critical thermal maximum $\left(\mathrm{CT}_{\mathrm{Max}}\right)$

Table 2

Summary of the effects of temperature, time and their interactions on survival in Glossina pallidipes

\begin{tabular}{llrl}
\hline Treatment & Effect & \multicolumn{1}{c}{$\chi^{2}$} & \multicolumn{1}{l}{$p$} \\
\hline Upper lethal temperatures & Temperature & 5.44 & $<0.05$ \\
& Time & 57.07 & $<0.0001$ \\
& Time $\times$ temperature & 57.45 & $<0.0001$ \\
Lower lethal temperatures & Temperature & 33.53 & $<0.0001$ \\
& Time & 29.35 & $<0.0001$ \\
& Time $\times$ temperature & 0.87 & 0.35 \\
\hline
\end{tabular}

Generalized linear model (Type III) analyses were performed assuming a binomial distribution with a logit link function in SAS and correcting for overdispersion. was defined as the onset of muscle spasms. A sample size of $n=10-20$ was used for all $\mathrm{CT}_{\mathrm{Max}}$ experiments and $n=20$ for $\mathrm{CT}_{\mathrm{Min}}$ experiments. All critical thermal limits data were assessed for normality of distributions (Shapiro-Wilks test) prior to analyses, and since these traits are known to be unaffected by factors such as gender, feeding status and post-developmental adult age in G. pallidipes (Terblanche et al., 2006) these variables were not incorporated into the analyses. Intra-specific variation in thermal tolerances in G. pallidipes was assessed by comparing the present data on the Mfuwe population with information on East African populations and laboratory-reared flies subjected to various acclimation treatments as reported previously in Terblanche et al. (2006) using one-way ANOVA (populations treated as a fixed effect) and Tukey-Kramer post hoc tests for homogeneity of groups.

To further assess the relationship between $\mathrm{CT}_{\mathrm{Max}}$ values and the environmental temperatures thought to compromise survival in this species (see Hargrove, 2001, 2004), we also report here the outcome of additional work undertaken to assess rate and starting temperature effects on $\mathrm{CT}_{\text {Max }}$ and $\mathrm{CT}_{\text {Min }}$ (Terblanche et al., submitted for publication). In this experiment, the protocols as described above were followed, but rather than using a single heating rate, we also investigated $\mathrm{CT}_{\text {Max }}$ and $\mathrm{CT}_{\text {Min }}$ following heating or cooling, respectively, at $0.25,0.12$ and $0.06^{\circ} \mathrm{C} / \mathrm{min}$. Starting temperatures for $\mathrm{CT}_{\text {Max }}$ included 35 , 38 and $41{ }^{\circ} \mathrm{C}$ while for $\mathrm{CT}_{\text {Min }}$ these included 16,20 and $24{ }^{\circ} \mathrm{C}$ (detailed in Terblanche et al. (submitted for publication)), but for the present study we only present data from a single starting temperature for each $\left(24^{\circ} \mathrm{C}\right.$ in $\mathrm{CT}_{\mathrm{Min}}$ and $35^{\circ} \mathrm{C}$ in $\mathrm{CT}_{\mathrm{Max}}$ ). Comparison of experimental treatment groups was made using one-way ANOVA (followed by Tukey-Kramer post hoc tests) for three different rates at upper and lower temperatures in order to illustrate these effects.

\subsection{Rapid cold hardening}

Rapid hardening responses were assessed using a plunge protocol similar to methods described previously (e.g. Kelty and Lee, 1999; Sinclair and Chown, 2003; Terblanche et al., 2007). To obtain a suitable discriminating temperature at which low but non-zero survival occurred, field-collected flies were sorted into non-airtight $60 \mathrm{ml}$ polypropylene vials in groups of 8-12 individuals and replicated a minimum of five times per temperature group. Groups were plunged into a water bath (Grant LTC-12 or LTD-6) at the set temperatures from 2 to $18{ }^{\circ} \mathrm{C}$ (in $2{ }^{\circ} \mathrm{C}$ increments) for $2 \mathrm{~h}$. Survival, defined as co-ordinated movement and response to a stimulus, was assessed after $4 \mathrm{~h}$ recovery at $30^{\circ} \mathrm{C}(76 \%$ r.h. $)$. A discriminating temperature of $2{ }^{\circ} \mathrm{C}$ was chosen as it produced low, but non-zero survival $(\sim 20 \%$ survival as estimated from preliminary experiments).

For the pre-treatments, flies were sorted into $60 \mathrm{ml}$ polypropylene vials in groups of $8-12$ per vial. Vials were 
placed in water baths $\left(8,10\right.$ and $14{ }^{\circ} \mathrm{C}$ pre-treatments $)$ or Peltier-controlled temperature cabinets (PTC-1) $\left(36^{\circ} \mathrm{C}\right.$ pretreatments). After $2 \mathrm{~h}$, vials were removed and immediately placed into a water bath set to $2^{\circ} \mathrm{C}$. After $2 \mathrm{~h}$ vials were removed from the water bath and transferred into a PTC-1 incubator set at $30^{\circ} \mathrm{C}(76 \%$ r.h. $)$ and survival was scored after $2 \mathrm{~h}$. This period was selected to minimize effects of mortality as a consequence of starvation. A replicated 'handling control' was included in each treatment group. The handling controls were subjected to sorting, placed into $30^{\circ} \mathrm{C}\left(76 \%\right.$ r.h.) for $2 \mathrm{~h}$, transferred to $2{ }^{\circ} \mathrm{C}$ for $2 \mathrm{~h}$, and then placed at $30^{\circ} \mathrm{C}$ for $2 \mathrm{~h}$ to allow recovery before scoring survival. Within each vial, relative humidity was carefully regulated during these experiments to $\sim 76 \%$. Inside each $60 \mathrm{ml}$ vial containing flies, a perforated $2 \mathrm{ml}$ plastic tube held damp cotton wool soaked in saturated $\mathrm{NaCl}$ solution and was affixed to the lid of the vial. The inner plastic tube prevented flies from coming into direct contact with the salt solution.

A variety of pre-treatments were undertaken to encompass a range of conditions which might stimulate hardening responses while remaining cognisant of the range of environmental temperature variation that might be experienced in tsetse habitats. These pre-treatments included gap, desiccation, controlled cooling rates and direct plunge treatments (see Fig. 1 for a schematic diagram). Gap treatments involved waiting $1 \mathrm{~h}\left(36^{\circ} \mathrm{C}\right)$ or $2 \mathrm{~h}\left(10^{\circ} \mathrm{C}\right.$ treatments) after pre-treatments before plunging groups into the discriminating temperature to allow full development of a possible heat shock protein response (for rationale see Sinclair and Chown, 2003). All experiments were performed under controlled relative humidity $(76 \%$ r.h.) except for the ' $36^{\circ}$ Dry' treatment which was undertaken at $<5 \%$ r.h. by including silica gel in vials and aimed to identify if desiccation could induce hardening. Cooling treatments were ramped at a constant cooling rate of $0.25^{\circ} \mathrm{C} / \mathrm{min}$ (LTC-12) after $10 \mathrm{~min}$ equilibration at $25^{\circ} \mathrm{C}$. The ' $10^{\circ} \mathrm{Cool} 45 \mathrm{~min}$ ' treatment was ramped down to $10{ }^{\circ} \mathrm{C}$ and transferred immediately to $2{ }^{\circ} \mathrm{C}$ for $2 \mathrm{~h}$. The duration of the latter treatment was therefore approximately $45 \mathrm{~min}$. By contrast, the ' $10^{\circ} \mathrm{Cool} 2 \mathrm{~h}$ ' treatment was cooled from $25^{\circ} \mathrm{C}$ (at $0.25^{\circ} \mathrm{C} / \mathrm{min}$ ) to $10^{\circ} \mathrm{C}$ but held for $2 \mathrm{~h}$ at this temperature before transferring flies to $2{ }^{\circ} \mathrm{C}$ for $2 \mathrm{~h}$. All other plunge treatments involved $2 \mathrm{~h}$ pre-treatments prior to exposure at the discriminating temperature. All statistical comparisons are made in a pairwise fashion using randomization statistics for pre-treatment versus control groups on a given day (as described in Terblanche et al. (2007)) and corrected for False Discovery Rates (FDRs) to reduce the likelihood of rejecting the null hypothesis falsely in multiple testing (Benjamini and Hochberg, 1995).

\subsection{Chill coma recovery times}

Flies were chilled in $60 \mathrm{ml}$ polypropylene vials using calibrated water baths set at $2{ }^{\circ} \mathrm{C}$ increments ranging from 2 to $12^{\circ} \mathrm{C}$ (following the methods described in David et al., 2003). Previous work on critical thermal limits in $G$. pallidipes field populations and laboratory colonies has suggested little effect of gender on temperature tolerance (Terblanche et al., 2006). However, since work on chill

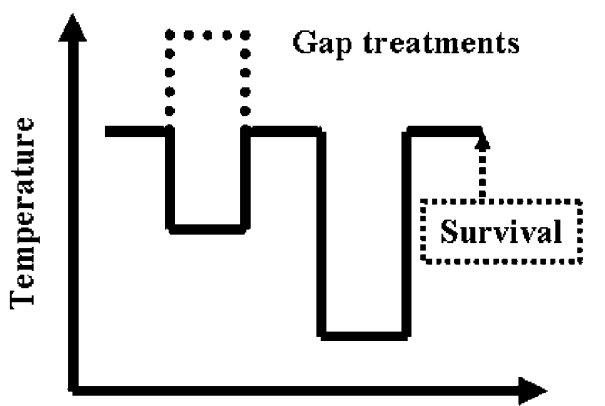

Time

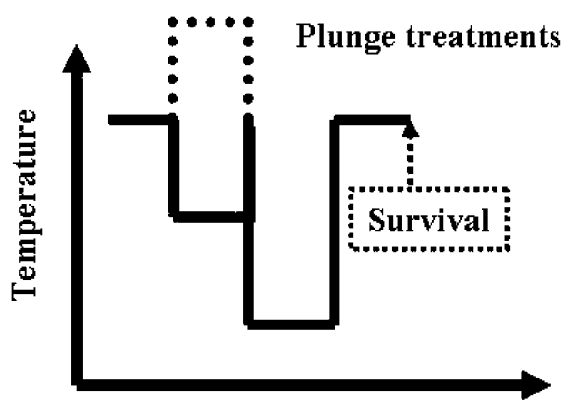

Time
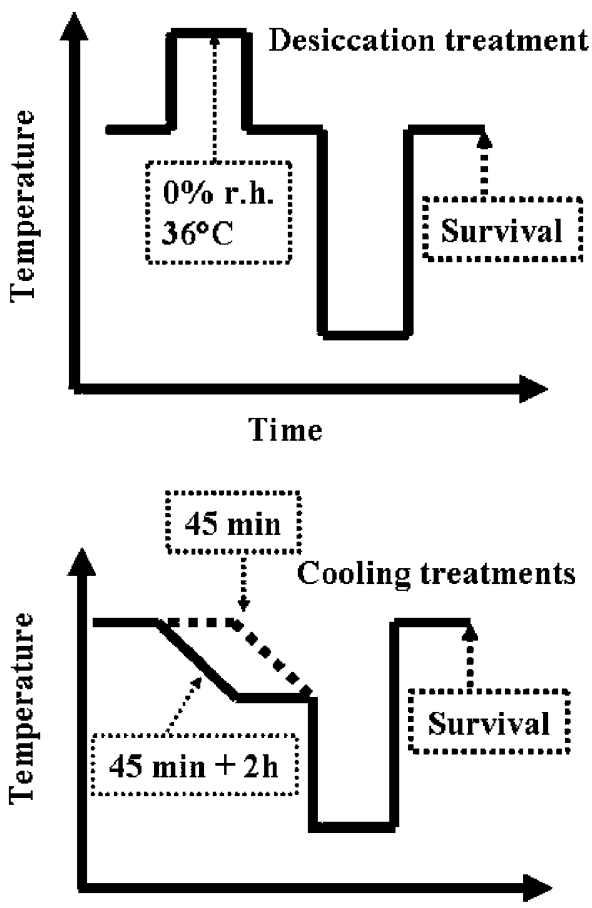

Time

Fig. 1. Schematic diagram of experimental protocols used to induce a hardening response (see Section 2.4 for a thorough description of each treatment). 
coma recovery time in Drosophila has found gender effects in some cases (David et al., 1998), but not in others (Gibert et al., 2001), and because no previous work on Glossina spp. has reported gender effects or a lack thereof in this trait, only female flies were used to avoid potentially confounding comparisons of treatment groups if sex ratios varied by chance. A $2 \mathrm{~h}$ period at the treatment temperatures was chosen as a compromise between complete recovery of all individuals upon return to ambient conditions and recovery occurring within too short a time span to record accurately. Essentially, field-collected flies were subjected to constant temperatures for $2 \mathrm{~h}$ and returned to ambient temperature where their recovery time was recorded. For each test temperature, five to six replicated vials $(n=10-20$ per vial) were used. Upon completion of the $2 \mathrm{~h}$ temperature exposure, flies were transferred onto paper towels in an open plastic container and recovery times were scored. The ability to fly or walk in a co-ordinated fashion was defined as 'recovery' and the time taken to achieve this was noted for each individual. As expected from the results of the lower lethal temperature experiments, many flies did not recover at the lower temperatures (often in excess of $70 \%$ at the lowest temperatures) even after an hour, and these flies were excluded from analyses. Thus, replication of experiments was necessary to obtain sufficient sample sizes. Upon recovery, flies were captured with soft forceps and weighed immediately to $0.1 \mathrm{mg}$ on an electronic balance (FA 304T, Avery Berkel, Fairmont, USA) to investigate potential relationships between body size and recovery time. Within each temperature treatment group linear regression analyses confirmed that recovery times were not related to body size $(p>0.1$ in all cases). Ambient laboratory temperatures $\left(T_{\mathrm{a}}\right)$ were recorded at the start and end of each experiment and varied by less than $2{ }^{\circ} \mathrm{C}$ between replicates and treatments $\left(T_{\mathrm{a}}: 35-37^{\circ} \mathrm{C}\right)$. Chill coma recovery times were $\log _{10}$ transformed to normalize the right-skewed frequency distributions that are typical of this trait (see David et al., 2003).

\subsection{Survival after exposure to the critical thermal minimum}

We next considered the potential costs of experiencing chill coma, which may be particularly apparent in chillsusceptible insects such as tsetse. Female flies were selected at random from traps and divided into two treatment groups. Survival times, at $30{ }^{\circ} \mathrm{C}$ and $76 \%$ r.h., were compared among flies which had and had not experienced chill coma. Individual flies were weighed to $0.1 \mathrm{mg}$, placed singly into polypropylene vials, and submerged in a water bath which lowered temperature at $0.25^{\circ} \mathrm{C} / \mathrm{min}$ after 12 min equilibration at $20^{\circ} \mathrm{C}$. Twenty flies were removed once the water bath reached $18^{\circ} \mathrm{C}$ and 20 flies were removed after the bath reached $8^{\circ} \mathrm{C}$. All flies were then placed individually into $60 \mathrm{ml}$ vials and held in a temperature cabinet (PTC-1) at $30{ }^{\circ} \mathrm{C}$ and $76 \%$ r.h. Survival time was scored every $2 \mathrm{~h}$ until all flies had died.
Thus, flies in these two groups had either been subjected to a temperature at which $\mathrm{CT}_{\mathrm{Min}}$ had been experienced $\left(8^{\circ} \mathrm{C}\right)$ or not experienced $\left(18^{\circ} \mathrm{C}\right.$ ) (see critical thermal limits results) and thus represented a group of individuals which had undergone chill coma vs. a group which had not. The difference in time between these two treatments was $\sim 40 \mathrm{~min}$ and starvation effects are therefore considered negligible between these two groups.

The influence of low-temperature events and body condition on survival was further explored to assess the possibility of physiological trade-offs between body condition and low temperature tolerance (as in Drosophila, Hoffmann et al., 2005). Here, female flies selected at random from traps $(n=20)$ were run as in Section 2.2 using the double-jacketed chambers but at the point of $\mathrm{CT}_{\text {Min }}$ (chill coma) induction the temperature was noted, the fly was removed from the system immediately, weighed, and transferred to individual, labelled vials. Flies were then placed into the temperature cabinet (PTC-1) at $30^{\circ} \mathrm{C}$ and $76 \%$ r.h. and survival time was scored every $2 \mathrm{~h}$ until all flies had died. At the time of death, flies were again weighed. After all individuals had died, flies were weighed, dried to constant mass $\left(50-60{ }^{\circ} \mathrm{C}, 0 \%\right.$ r.h. $)$ and weighed again to estimate body water content. Subsequently, body lipid extractions were performed on these individuals using standard chloroform: methanol (1:1) solvent extraction techniques. Lipid content was defined as the dry mass of the fly prior to lipid extraction subtracted from its dry, lipid-free mass (termed 'residual dry mass'; as described in Terblanche et al., 2006). Regression analyses (Type III model) were undertaken in Statistica 7.0 (Statsoft, OK, USA) to determine if a relationship existed between low temperature tolerance ( $\mathrm{CT}_{\mathrm{Min}}$ as the dependent variable), body condition (either water or fat content) and survival time following chill coma.

\section{Results}

\subsection{High-temperature responses}

Time and temperature had a significant effect on survival at high temperatures and the interaction between time and temperature was also significant (Table 2; Fig. 2A). Here, longer exposure time or more severe temperatures resulted in a reduction in high-temperature survival, but the form of the relationship between temperature and survival differed depending on exposure time. The temperature at which $50 \%$ of the population survived (Upper Lethal Temperature, $\mathrm{ULT}_{50}$ ) for the 1,2 and $3 \mathrm{~h}$ treatments was $37.9,36.2$ and $35.6{ }^{\circ} \mathrm{C}$, respectively $\left(95 \%\right.$ CIs: $\left.\pm 0.5^{\circ} \mathrm{C}\right)$.

Upper critical thermal limits were influenced substantially by the rate of temperature change (Fig. 3A). Mean heating rates calculated from shaded microclimate data for fly resting sites (verified by observation) were $0.050 \pm$ $0.010^{\circ} \mathrm{C} / \mathrm{min}$ (mean \pm S.D.; $n=10$ days). Therefore, the slowest heating rates $\left(0.06^{\circ} \mathrm{C} / \mathrm{min}\right)$ starting from a temperature approximating ambient conditions $\left(35^{\circ} \mathrm{C}\right)$ 
A

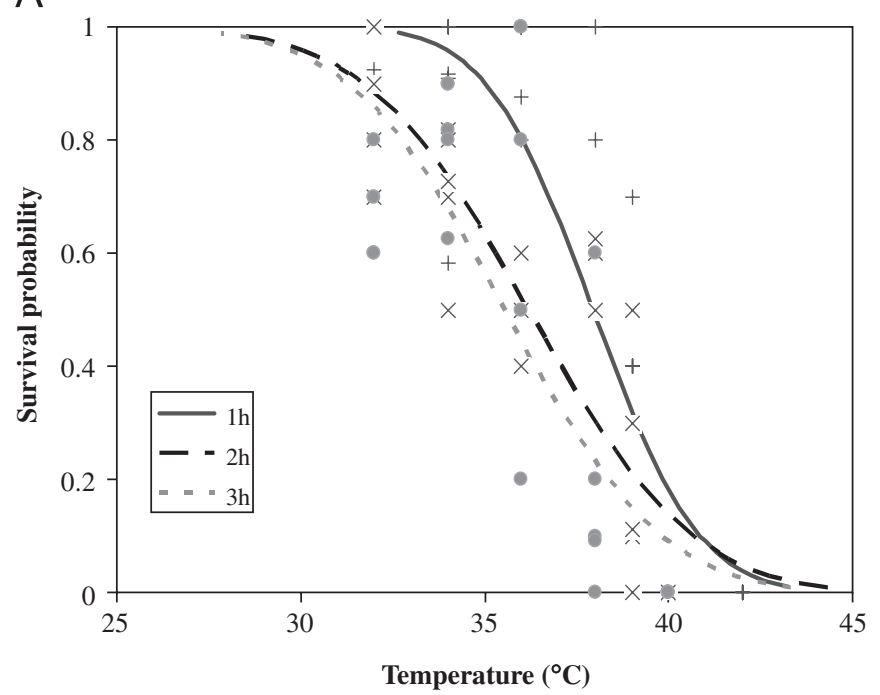

B

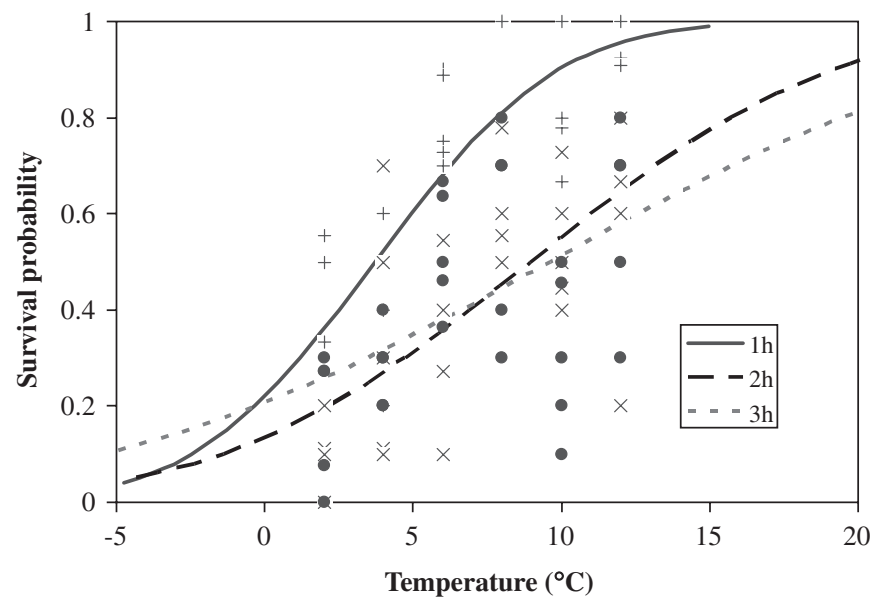

Fig. 2. Survival probability of Glossina pallidipes to (A) high or (B) low temperatures for 1,2 or $3 \mathrm{~h}$ treatments. Curves of survival probability data were derived from SAS probit (non-linear) analyses. The raw survival data from several replicates ( $n=5-8$ per treatment temperature) where each replicate contained $n=8-12$ individual flies are plotted on the same axes. The raw data 1,2 and $3 \mathrm{~h}$ treatments are represented by addition symbols $(+)$, crosses $(\times)$, and filled circles $(\bullet)$, respectively.

represent the temperature tolerance estimates most ecologically relevant to $G$. pallidipes in its natural thermal environment (Terblanche et al., submitted for publication).

\subsection{Low-temperature responses}

\subsubsection{Low-temperature tolerance}

The effects of temperature and time on survival were significant such that more severe temperatures or longer durations at a given temperature resulted in lower survival (Fig. 2B). However, interactions between time and temperature were not significant, indicating that the form of the relationship between temperature and survival did not depend on exposure time (Table 2), even though initial inspection of the data suggested that this might be the case. High variances in the low temperature data likely account

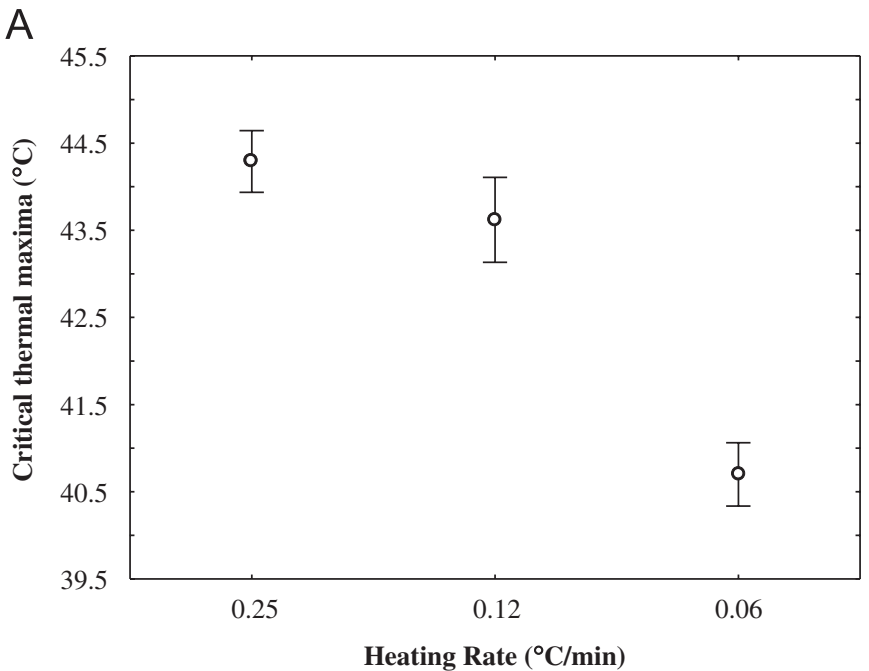

B

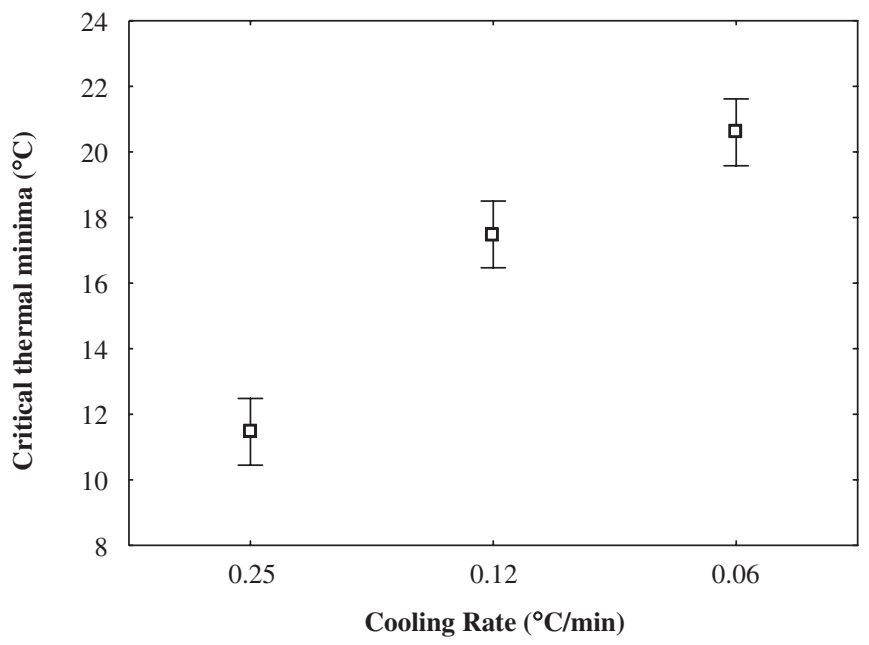

Fig. 3. The effect of rate of temperature change on critical thermal limits in Glossina pallidipes. (A) Upper critical thermal limits ( $\pm 95 \%$ confidence limits) obtained from a $35^{\circ} \mathrm{C}$ starting temperature for $12 \mathrm{~min}$ at three heating rates (ANOVA, $p<0.0001$ ). (B) Lower critical thermal limits $\left( \pm 95 \%\right.$ confidence limits) obtained from a $24{ }^{\circ} \mathrm{C}$ starting temperature for $12 \mathrm{~min}$ (ANOVA, $p<0.0001$ ).

for this finding. The temperatures at which $50 \%$ of the population survived the low-temperature range (lower lethal temperature, $\mathrm{LLT}_{50}$ ) for 1,2 and $3 \mathrm{~h}$ treatments were $3.7,8.9$ and $9.6{ }^{\circ} \mathrm{C}$, respectively $(95 \%$ CIs were $\left.\pm 1.5^{\circ} \mathrm{C}\right)$.

Low-temperature critical thermal limits starting from $24^{\circ} \mathrm{C}$ are profoundly influenced by the experimental protocol such that a reduction in cooling rate results in higher $\mathrm{CT}_{\text {Min }}$ values (Fig. 3B). Mean cooling rates calculated from microclimate data during the study period were $0.020 \pm 0.007^{\circ} \mathrm{C} / \mathrm{min}($ mean \pm S.D.) across a 10 -day period. Again, the slowest rate of cooling can be regarded as the most ecologically relevant one to assess likely chill coma in the wild.

Flies recovered slowest from chill coma after the lowest temperature exposure, although this relationship was clearly non-linear across the range of temperatures 


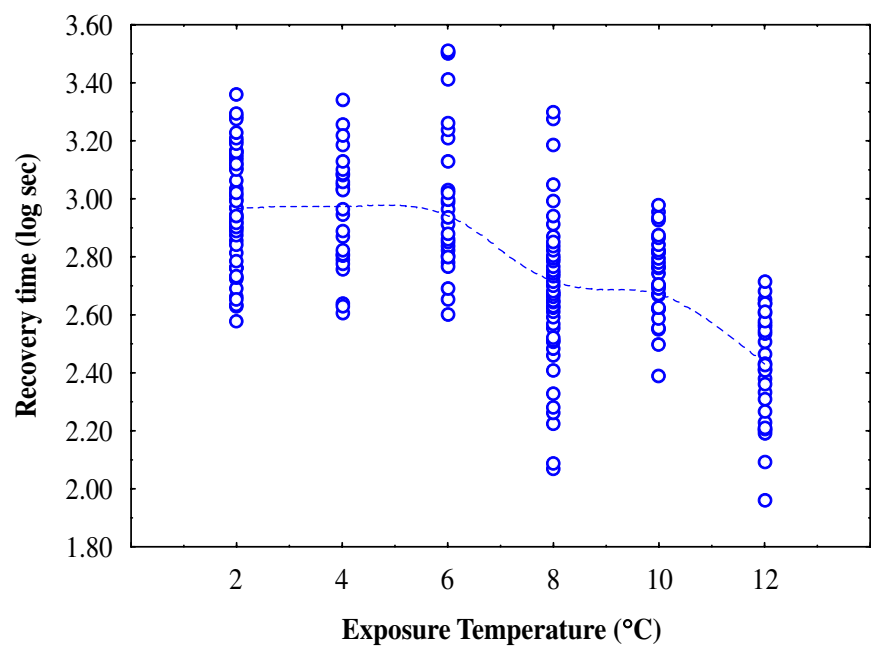

Fig. 4. Recovery times of Glossina pallidipes after $2 \mathrm{~h}$ exposure at different test temperatures. Distance-weighted least-squares line was fitted using Statistica analysis software.

investigated (Fig. 4). In consequence, chill coma recovery times were strongly influenced by the temperature of exposure (GLZ in SAS, poisson distribution, log link function, d.f. $=1,187$, Wald $\left.\chi^{2}=25386.2, p<0.0001\right)$.

\subsubsection{Low-temperature plasticity: a lack of hardening response}

No evidence of rapid cold hardening in response to several low- or high-temperature treatments, desiccation, or treatments with gaps (delays) was found ( $p>0.73$ after FDR correction in all cases), with the exception of the group cooled to $10^{\circ} \mathrm{C}$ and immediately subjected to the discriminating temperature $\left(' 10{ }^{\circ} \mathrm{C} \mathrm{Cool} 45 \mathrm{~min}\right.$ ', $t=4.235$, $p<0.0001$ after FDR correction). However, this group experienced almost one third of the time during pretreatment by comparison with the other groups (Fig. 5), and the seemingly positive effect of pre-treatment may actually have been a consequence of a reduction in duration, and thus severity, of the temperature exposure. Indeed, as soon as time was controlled for in a similar experiment in which flies were similarly cooled but held at $10{ }^{\circ} \mathrm{C}$ for $2 \mathrm{~h}$ prior to plunging into the discriminating temperature (' $10^{\circ} \mathrm{C}$ Cool $2 \mathrm{~h}$ ' treatment), survival was not significantly improved relative to the control group $(t=-1.672, p>0.72$ after FDR correction).

\subsubsection{Chill coma, body condition and survival time}

No difference in mean subsequent survival time was evident between the group which had experienced chill coma compared with the group which had not $\left(F_{1,38}=\right.$ $0.44, p>0.51)$ even after correction for body condition (body lipid content and water content summed) $\left(F_{1,37}=\right.$ $0.43, p>0.51)$, body water content $\left(F_{1,37}=0.44, p>0.51\right)$ or lipid content (residual dry mass) $\left(F_{1,37}=0.41, p>0.50\right)$.

In the group used to test for a relationship between cold tolerance and body condition, a weak negative relationship

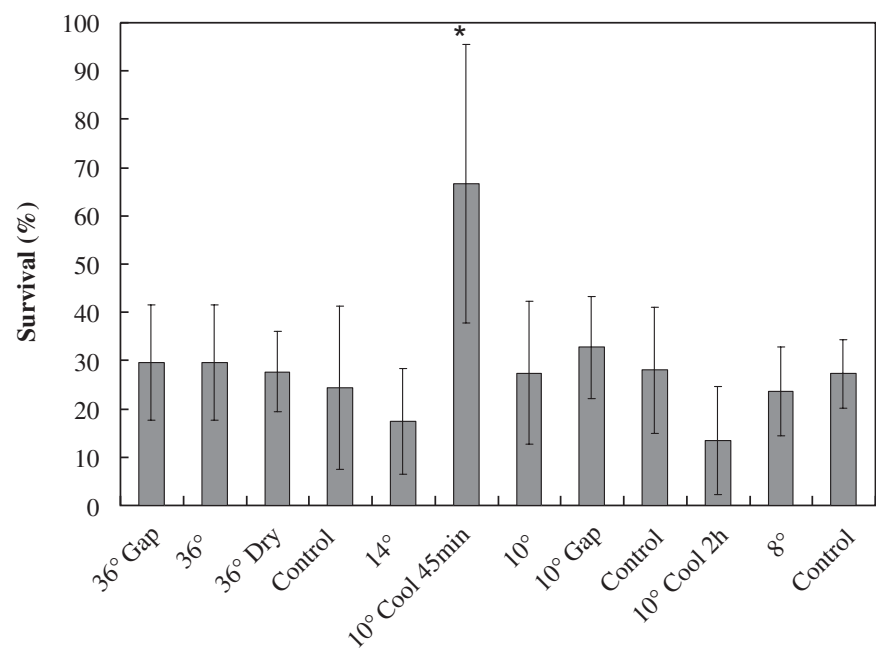

Fig. 5. The effects of short-term $(\sim 2-4 \mathrm{~h})$ acute pre-treatments on survival at a discriminating temperature of $2{ }^{\circ} \mathrm{C}$ for $2 \mathrm{~h}$ in Glossina pallidipes. All treatments were non-significant except in the ' $10^{\circ} \mathrm{Cool} 45 \mathrm{~min}$ ' treatment (see text for Section $3 ;{ }^{*} p<0.0001$ even after false discovery rate correction). Treatment descriptions are given in full in Section 2.4.

was obtained between $\mathrm{CT}_{\mathrm{Min}}$ and survival time $\left(r^{2}=0.25\right.$; $\left.F_{1,18}=5.99 ; \quad p<0.05\right)$ indicating that the least lowtemperature tolerant flies were the first to die of starvation. Flies which begun experiments with higher body water content had an advantage during the survival assays as they could resist desiccation for longer. As expected, a positive relationship was found between body water content and survival time $\left(r^{2}=0.51 ; \quad F_{1,18}=18.94\right.$; $p<0.001)$. However, no relationship was found between $\mathrm{CT}_{\mathrm{Min}}$ and residual (fat-free) dry mass $\left(F_{1,18}=0.44\right.$, $p>0.51)$. Thus, little support for a trade-off between starvation resistance and chill coma temperatures in female G. pallidipes was found.

\subsection{Inter-population comparison: data synthesis}

\subsubsection{High-temperature responses}

Because work on the Kenyan and laboratory-acclimated populations was undertaken using a $0.25^{\circ} \mathrm{C} / \mathrm{min}$ heating rate and experimental protocol started at $35^{\circ} \mathrm{C}$ (Terblanche et al., 2006), we could only make a comparison between this study and the previous one with the $\mathrm{CT}_{\mathrm{Max}}$ data obtained using the same heating rate and start temperature. This comparison revealed significant variation in $\mathrm{CT}_{\text {Max }}$ among wild populations (ANOVA: $\left.F_{4,134}=8.539, p<0.0001\right)$, although the full range of variation among all laboratory treatments and field populations was only (ca.) $1{ }^{\circ} \mathrm{C}$ (Table 3 ). $\mathrm{CT}_{\text {Max }}$ values for flies from various temperature acclimation treatments (after 10 days; Lab19-29) fell within the range of the East African population values, and in general acclimation treatments had little effect on $\mathrm{CT}_{\mathrm{Max}}$ even though the $19^{\circ} \mathrm{C}$ acclimation group was identified as being statistically 
different from the $29^{\circ} \mathrm{C}$ acclimation group in the full ANOVA (Table 3; Terblanche et al., 2006).

\subsubsection{Low temperature responses}

Using population data from our previous study combined with the present study (all data obtained using a similar cooling rate $\left(0.25^{\circ} \mathrm{C} / \mathrm{min}\right)$ and starting temperature $\left.\left(16^{\circ} \mathrm{C}\right)\right), \mathrm{CT}_{\mathrm{Min}}$ differed among populations with an overall

Table 3

Summary data for field populations and laboratory acclimation treatments of critical thermal limits in Glossina pallidipes

\begin{tabular}{llllll}
\hline Population & $\begin{array}{l}\text { Critical thermal } \\
\text { maxima }\end{array}$ & & & $\begin{array}{l}\text { Critical thermal } \\
\text { minima }\end{array}$ \\
\cline { 2 - 3 } \cline { 5 - 6 } & $\begin{array}{l}\text { Mean } \pm \text { S.E. } \\
\left({ }^{\circ} \mathrm{C}\right)\end{array}$ & $N$ & & $\begin{array}{l}\text { Mean } \pm \text { S.E. } \\
\left({ }^{\circ} \mathrm{C}\right)\end{array}$ & $N$ \\
\cline { 1 - 2 } Lambwe, Kenya & $44.6 \pm 0.1^{\mathrm{A}, \mathrm{C}}$ & 30 & & $13.4 \pm 0.2^{\mathrm{A}}$ & 30 \\
Narok, Kenya & $44.4 \pm 0.1^{\mathrm{A}}$ & 30 & & $10.5 \pm 0.2^{\mathrm{B}}$ & 30 \\
Nguruman, Kenya & $44.9 \pm 0.1^{\mathrm{C}}$ & 30 & & $13.8 \pm 0.2^{\mathrm{A}}$ & 30 \\
Kwale, Kenya & $45.0 \pm 0.1^{\mathrm{C}}$ & 30 & & $13.8 \pm 0.2^{\mathrm{A}}$ & 30 \\
Mfuwe, Zambia & $\mathbf{4 4 . 3} \pm \mathbf{0 . 1} \mathbf{1}^{\mathrm{A}, \mathbf{B}}$ & $\mathbf{2 0}$ & & $\mathbf{1 3 . 0} \pm \mathbf{0 . 2 ^ { \mathbf { A } }}$ & $\mathbf{2 0}$ \\
Lab19 & $43.9 \pm 0.1^{\mathrm{B}}$ & 20 & & $4.5 \pm 0.2^{\mathrm{C}}$ & 20 \\
Lab24 & $44.4 \pm 0.2^{\mathrm{A}, \mathrm{B}, \mathrm{C}}$ & 10 & & $7.8 \pm 0.3^{\mathrm{D}}$ & 12 \\
Lab29 & $44.2 \pm 0.1^{\mathrm{A}, \mathrm{B}}$ & 19 & & $7.2 \pm 0.2^{\mathrm{D}}$ & 20 \\
\hline
\end{tabular}

Mfuwe-Zambia, this study; Lambwe, Narok, Nguruman, KwaleKenya; Lab19-laboratory colony reared at $19^{\circ} \mathrm{C}$ for 10 days as adults; Lab24 - laboratory colony reared at $24^{\circ} \mathrm{C}$ for 10 days as adults; Lab29laboratory colony reared at $29^{\circ} \mathrm{C}$ for 10 days as adults; source: Terblanche et al. (2006). For detailed description of Kenyan populations sampling sites, laboratory acclimation procedures and statistics, see Terblanche et al. (2006). All data obtained using identical experimental procedures (rate of temperature change: $0.25^{\circ} \mathrm{C} / \mathrm{min}$; starting temperature: $35^{\circ} \mathrm{C}$ and $16{ }^{\circ} \mathrm{C}$ for critical thermal maxima and minima, respectively). Data from the present study is given in bold font. Superscript letters indicate statistically homogeneous groups after ANOVA followed by Tukey-Kramer post hoc tests. Statistics for comparisons of natural populations only (i.e., excluding laboratory colony flies) are reported in Section 3.

${ }^{\mathrm{a}} F_{7,181}=12.93 ; p<0.0001$.
${ }^{\mathrm{b}} F_{7,214}=338.26 ; p<0.0001$. range of $\sim 3.5^{\circ} \mathrm{C}$ (Table 3). However, this was largely due to the high-altitude Narok population from Kenya (ANOVA: $F_{4,135}=43.181, p<0.0001$ ) as the remaining populations were homogeneous. In the laboratory flies, $>3{ }^{\circ} \mathrm{C}$ variation could be induced by temperature acclimation, although some differences in absolute low temperature tolerance is evident between colony-reared and natural populations assayed under identical conditions (Table 3; Terblanche et al., 2006).

\section{Discussion}

\subsection{Thermal limits, mortality, and geographic range}

Temperature tolerance has long been a topic of interest to biologists investigating tsetse, given indications that high temperatures have negative effects on populations of these species (summarized in Bursell, 1964; Leak, 1999; Hargrove, 2004; see also Hargrove, 2001; Table 4). Typically, physiological estimates of high-temperature tolerance are substantially higher than the estimates of survival probability derived from mark-recapture studies in tsetse. For example, experimental work in G. palpalis, Glossina tachinoides and Glossina morsitans submorsitans has suggested upper lethal limits of approximately 40-44 ${ }^{\circ} \mathrm{C}$ (Buxton and Lewis, 1934; Mellanby, 1936), whilst in the field, population declines commence at temperatures at least $12{ }^{\circ} \mathrm{C}$ lower in G. m. morsitans and G. pallidipes (Hargrove, 2001, 2004). Thus, it might at first appear that physiological tolerances have little direct role to play in determining tsetse demographics or distributions (see Torr and Hargrove, 1999), despite the strong relationships between temperature variables and distributions and abundance found in correlative studies (e.g. Robinson et al., 1997a, b; Hendrickx et al., 1999). Based solely on our results for critical thermal maximum (Table 3), one might again suggest that this is the case though little variation among populations does provide one mechanism by which distributions may be limited by little evolutionary

Table 4

Summary of thermal biology studies undertaken on tsetse flies (Glossina spp.) from the Anglophone literature

\begin{tabular}{|c|c|c|c|c|}
\hline Species & Physiological trait & Life stage & Source & Reference \\
\hline G. morsitans & ULT, cold survival, heat survival & Pupae/adults & Laboratory/field & Potts (1933) \\
\hline G. tachinoides, G. m. submorsitans & ULT, LLT & Pupae/adults & Field & Buxton and Lewis (1934) \\
\hline G. morsitans & LLT & Pupae & Field & Bursell (1960) \\
\hline G. morsitans & Survival times, ULT & & & Jack (1942) \\
\hline G. palpalis & Survival, $\mathrm{CT}_{\mathrm{Min}} /$ activity $^{\mathrm{c}}$ & Adults & Field & Mellanby (1936) \\
\hline G. palpalis & Survival, $\mathrm{CT}_{\mathrm{Min}} / \mathrm{CT}_{\mathrm{Max}} /$ activity $^{\mathrm{c}}$ & Adults & Field & Macfie (1912) \\
\hline G. palpalis & Cold survival & Adults & Field & Burnett (1957) \\
\hline
\end{tabular}

${ }^{\text {a }}$ Colony supplemented with field flies.

${ }^{\mathrm{b}}$ Cited in Phelps and Burrows (1969).

${ }^{\mathrm{c}}$ May approximate critical thermal limits. 
change of flexibility (Terblanche et al., 2006). However, we are of the opinion that experimental protocol contributes to the discrepancy between field and laboratory studies.

Two lines of evidence suggest that this is the case. First, prolonged exposures to high temperatures result in a substantial decline in survival (ca. $40 \%$ at $35^{\circ} \mathrm{C}$; Fig. $2 \mathrm{~A}$ ), suggesting that even longer exposures to moderately high temperatures might result in substantial mortality. This has been found previously in G. palpalis (Mellanby, 1936). Second, when heating rates are reduced to those typically experienced by field flies, and starting temperatures are more typical of the field Ta, cessation of activity via heat coma also falls within the range of values typical of field conditions (cf. Fig. 3A with Fig. 6). These results, together with the limited flexibility in critical thermal limits shown by G. pallidipes (Table 3), suggest that the direct negative effects of high temperature may well play an important role in reducing survival in the field (see Hargrove, 2004), and setting geographic range limits in this species as the correlative data suggests (Robinson et al., 1997a,b). However, because mortality rates typically start increasing from a mean temperature of approximately $27^{\circ} \mathrm{C}$ in the field (Hargrove, 2004), and because metabolic rates are also strongly related to temperature (Terblanche et al., 2005; Terblanche and Chown, 2007) and influence internal resource availability (Bursell and Taylor, 1980), indirect effects of temperature might also be important (discussed in Torr and Hargrove (1999)). Specifically, it seems likely that, as Hargrove (2004) proposed, feeding to make up internal resource shortages (precipitated by enhanced metabolic costs at high temperature) is likely to elevate predation risk, resulting in enhanced mortality. What the

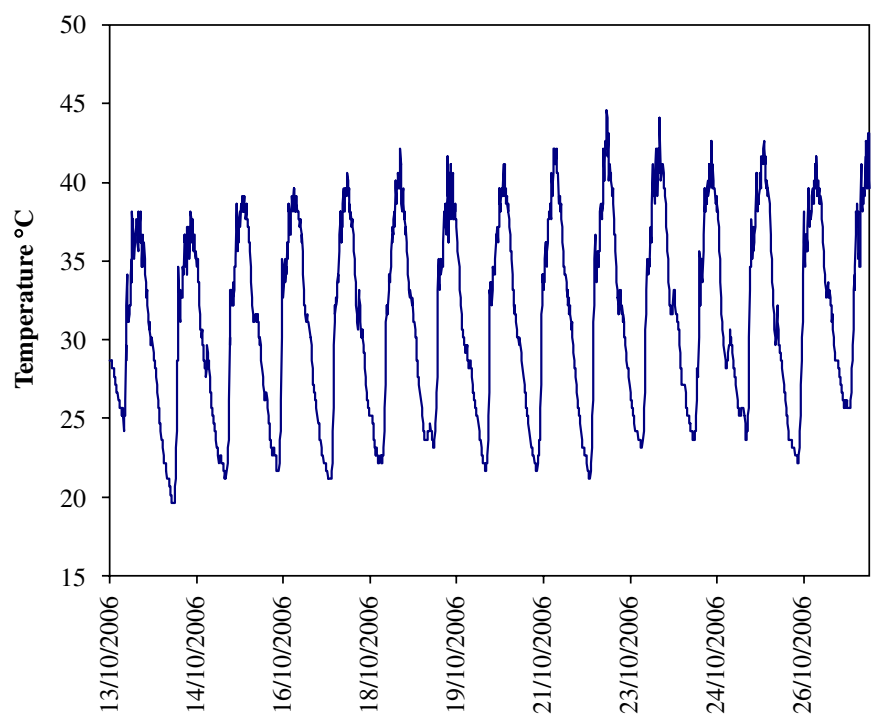

Fig. 6. Microclimate data representative of Glossina pallidipes habitat gathered during a 2-week period in October 2006 in South Luangwa National Park, Zambia (using Thermochron iButtons, Dallas, TX, USA; resolution $0.1^{\circ} \mathrm{C}$ ). relative contributions are of these mortality factors has yet to be ascertained. Although thermal refugia might enable tsetse to live at temperatures $2-6{ }^{\circ} \mathrm{C}$ lower than ambient values (Torr and Hargrove, 1999; Muzari and Hargrove, 2005), maximum temperatures might still reach values close to those of the absolute limits of individual flies. Irrespective, the available physiological and environmental data (Terblanche et al., 2006; Hargrove, 2001, 2004) support the prediction that, at least in south-eastern Africa, the geographic range of $G$. pallidipes is likely to decline with warming climates, as has been predicted for other species of tsetse (see Hulme, 1996; Rogers and Robinson, 2004; but see Rogers and Randolph, 1993).

At the other end of the temperature range, the lower lethal limit data and $\mathrm{CT}_{\mathrm{Min}}$ data at the slowest cooling rates suggest that at temperatures as high as $20^{\circ} \mathrm{C}$, adult flies might either experience mortality, or might be unable to be active, respectively. In the case of limits to activity, the co-occurrence of low-temperature periods and those of minimal tsetse activity (all species are diurnal foragers although they readily adjust peaks in activity time to microclimate temperatures - see, for example, Huyton and Brady, 1975; Hargrove and Brady, 1992) mean that relatively high cold stupor temperatures are unlikely to negatively influence adult survival in areas that have high diurnal temperatures. Likewise, the mortality effects of low temperature in such regions might be mitigated by selection of thermal refugia (Muzari and Hargrove, 2005), so resulting in little change in daily mortality rates with declining temperatures as typically found in such areas (see, for example, Hargrove, 2004). However, the lower thermal limits documented here might explain the absence of tsetse from cooler, high elevation or more southerly regions (discussed in Bursell (1960); and see, for example, Rogers and Packer, 1993; Hulme, 1996). Even though it has previously been claimed that limits to pupal development (Glossina spp. typically do not emerge below $14-16^{\circ}$ (Bursell, 1960; Phelps and Burrows, 1969)) might set in before low temperature limits to adult survival and activity (Bursell, 1964), our data show that this is unlikely to be the case for $G$. pallidipes. Rather, activity can be limited at temperatures as high as $22^{\circ} \mathrm{C}$, and mortality already sets in between 14 and $18^{\circ} \mathrm{C}$ in adults. Whilst tsetse may be able to circumvent low temperature mortality and the negative effects of low temperature on pupal development rate by selection of appropriate thermal refuges (Bursell, 1959, 1960; Torr and Hargrove, 1999; Muzari and Hargrove, 2005), the use of the same refuges for both purposes must mean that the stage with the greatest sensitivity to temperature would be affected first. Moreover, adult tsetse are unable to survive for longer than 4-6 days without a blood meal even at relatively low temperatures (Buxton and Lewis, 1934; Jackson, 1954). If ambient temperatures remain below the critical limits for activity for longer than this period, then clearly mortality will increase substantially, making adult thermal tolerance rather than the temperature sensitivity of pupal development most sig- 
nificant in affecting survival, and ultimately for limiting geographic range in low-temperature areas (see Bursell, 1960; Hargrove and Brady, 1992). Nonetheless, substantial plasticity in critical thermal limits (see Table 3) might partially mitigate the effects of low temperatures on adult activity. Indeed, this might provide an ultimate explanation for why substantial plasticity exists in lower, but not in upper critical limits, and why plasticity effects are so much larger in the adult than in the pupal stage (Terblanche and Chown, 2006). Nonetheless, these data suggest that increasing temperatures are likely to affect tsetse population dynamics and distributions not only via the pupal stage, but also via mortality effects on adults. Hence, bottom-up modelling work (e.g. Hargrove and Williams, 1998) must take cognisance of the likely significance of thermal biology of the adults.

\subsection{Rapid cold hardening and chill coma recovery}

By contrast with the longer term acclimation effects (see Terblanche et al., 2006; Terblanche and Chown, 2006), the hardening experiments in the present study suggest that G. pallidipes are characterized by little plasticity of acute low-temperature tolerance at short (hourly) time scales. Similar results have been obtained in laboratory colonies of G. pallidipes and Glossina fuscipes (see FAO/IAEA, 2002). Little or no hardening has been documented in other terrestrial arthropod species, but these are typically from polar environments. For example, the sub-Antarctic caterpillar Pringleophaga marioni and adults of the kelp fly Paractora dreuxi show little change in survival of a low temperature following exposure to sub-lethal temperature pre-treatments (Sinclair and Chown, 2003; Terblanche et al., 2007). Likewise, the Arctic collembolan Hypogastrura tullbergi shows limited improvement in survival of lethal low temperatures following low-temperature pre-treatments (Hawes et al., 2006), as do adults of the Antarctic midge Belgica antarctica (Lee et al., 2006). Quite why these species and the tropical G. pallidipes should show little or no rapid cold hardening response, whilst the majority of other species investigated to date do (see Chown and Nicolson, 2004; Sinclair and Chown, 2006) is not clear. However, the similarity of the species in this respect might be entirely coincidental given that the presence or absence of rapid cold hardening is likely to be affected by the cold tolerance strategy typically adopted by the species (Sinclair and Chown, 2003, 2006), the duration of the stage (Lee et al., 2006), predictability and variability of the environment (Hawes et al., 2006), and the mobility and activity period of the adults relative to periods of low temperature (Terblanche et al., 2007).

In the case of chill coma recovery times, the non-linear patterns documented for $G$. pallidipes, with plateaus at 2-6 and $8-10^{\circ} \mathrm{C}$, are similar to those found in Drosophila, although the absolute temperature ranges differ. David et al. (2003) found a plateau in recovery times in the range of -4 to $-6{ }^{\circ} \mathrm{C}$ in Drosophila subobscura and suggested that this plateau was governed by the interplay of two distinct physiological mechanisms acting at different temperatures. In Drosophila melanogaster, MacDonald et al. (2004) also found evidence for a recovery time plateau but in the range of 2 to $-2{ }^{\circ} \mathrm{C}$ depending on the duration of exposure, and they suggested that rapid cold hardening responses may play a role in determining the plateau in recovery time. However, because G. pallidipes does not show $\mathrm{RCH}$, it seems unlikely that hardening responses are responsible for the plateau in chill coma recovery times. To date, only a few studies have investigated these non-linear effects (see Rako and Hoffmann, 2006; Chown and Terblanche 2007 and references therein) and the mechanisms underlying them remain obscure.

\subsection{Costs to chill coma and the influence of body condition}

Since G. pallidipes cannot rapidly cold harden, at least not under the conditions examined in the present study, it is highly likely they will experience chill coma with diurnal temperature variation under natural field conditions. For example, inspection of climate data (Table 5) and $\mathrm{CT}_{\mathrm{Min}}$ in the Mfuwe population (Table 3 and Fig. 3B) suggest that this is the case during certain times of the year (e.g. July) under the experimental conditions reported in the present study. Regardless, a separate study (Terblanche et al., submitted for publication) which investigates the effects of varying start temperatures, rates of temperature change and their interactions on critical thermal limits suggests that under the most ecologically relevant experimental conditions wild flies are highly likely to experience chill coma or heat stupor on multiple occasions during the course of the year. It is therefore relevant to consider the potential costs of experiencing chill coma, which may be

Table 5

Summary of annual weather data for Mfuwe, Zambia taken from interpolated weather station data using DIVA-GIS software over 1950-2000 (for details on interpolation methods and climatic variables, see Hijmans et al. (2005))

\begin{tabular}{lllc}
\hline & $T_{\min }\left({ }^{\circ} \mathrm{C}\right)$ & $T_{\max }\left({ }^{\circ} \mathrm{C}\right)$ & Rainfall $(\mathrm{mm})$ \\
\hline January & 20.1 & 30.6 & 220 \\
February & 20.0 & 30.3 & 195 \\
March & 19.5 & 30.7 & 130 \\
April & 17.7 & 30.4 & 40 \\
May & 14.2 & 29.2 & 3 \\
June & 11.2 & 27.6 & 0 \\
July & 10.8 & 27.8 & 0 \\
August & 12.7 & 29.8 & 0 \\
September & 16.2 & 33.5 & 0 \\
October & 19.4 & 35.5 & 13 \\
November & 20.6 & 34.8 & 86 \\
December & 20.3 & 31.5 & 178 \\
Annual & 16.9 & 31 & 865 \\
\hline
\end{tabular}

$T_{\min }$, minimum temperature within the month; $T_{\max }$, maximum temperature within the month. 
particularly apparent in chill-susceptible insects such as tsetse. For example, costs to growth, development rate, and final body size have been associated with repeated freezing and thawing in the freeze-tolerant caterpillar $P$. marioni (Sinclair and Chown, 2005). In the present study, the chill coma survival experiments suggests there are few shortterm costs and that $G$. pallidipes can survive for similar durations whether they have experienced chill coma as compared with no chill coma even after factoring body condition into the analyses. This is in keeping with findings from studies of other tsetse species. For example, in G. submorsitans and G. tachinoides, Buxton and Lewis (1934) reported that $2 \mathrm{~h}$ exposures at 4 or $8^{\circ} \mathrm{C}$ resulted in no long-term effects on survival, and that flies were capable of normal feeding behaviour upon return to ambient temperature. However, energy resources are increasingly being highlighted for their role in cold tolerance, as demonstrated by proline metabolic enzyme inhibition reducing a rapid cold hardening response (Misener et al., 2001), the role of energy reserves in surviving cold exposure (Colinet et al., 2006) and the trade-off between starvation resistance and cold tolerance (Hoffmann et al., 2005). In G. pallidipes, at short time scales it appears that there are few direct effects of chill coma on survival. However, the negative relationship between body condition and critical thermal minimum suggests an important role for energy and/or water reserves in determining low temperature tolerance. Under conditions of low host availability or infrequent feeding flies should be particularly susceptible to low temperature effects. Regardless, in G. pallidipes little direct evidence was found for trade-offs between starvation resistance and low-temperature tolerance since the most low temperature tolerant individuals had the greatest starvation resistance, not the converse.

In conclusion, this work on $G$. pallidipes, as well as previous studies on this species and G. morsitans (e.g. Terblanche et al., 2005, 2006; Terblanche and Chown, 2006, 2007), suggest that both direct and indirect physiological mechanisms could lie at the heart of the relationship between environmental variation and the distribution and abundance of tsetse. In particular, the southern and highaltitude limits to tsetse distributions, which have long concerned those working on the group (e.g. Rogers and Williams, 1994), may be explained on the basis of limits to adult survival and activity, as well as limits to development. These findings suggest that climate envelope modelling should provide a useful first step for analyzing the likely change in tsetse distributions with climate change. Of course, realized range alterations will depend also on the availability of hosts and on the flexibility of tsetse behaviour (see Robays et al., 2004). Our work also suggests that G. pallidipes has limited scope for short-term (hours) acclimation to low-temperature treatments; rendering any concerns about recovery effects during chilling for SIT irrelevant. However, longer-term, low temperature acclimation effects differentiate laboratory and field populations of these flies.

\section{Acknowledgements}

We are grateful to Charlene Janion (Centre for Invasion Biology) and Patsy and Herman Miles of the Wildlife Camp, for excellent logistic support at several stages in the project. John Mashili and John Silutongwe aided with trapping, collection and fly identification and our Zambia Wildlife Authority scout, Wisdom Kakumbwe, provided watchful eyes and safety during several close encounters. The referees are thanked for their comments. This work was supported by the DST-NRF Centre of Excellence for Invasion Biology and by National Institutes of Health Grant AI-52456 to E.S. Krafsur.

\section{References}

Benjamini, Y., Hochberg, Y., 1995. Controlling the false discovery rate: a practical and powerful approach to multiple testing. Journal of the Royal Statistical Society B 57, 289-300.

Bourne, D., Reid, R.S., Rogers, D.J., Snow, W.F., Wint, W., 2001. Environmental Change and the Autonomous Control of Tsetse and Trypanosomiasis in Sub-Saharan Africa. Environmental Research Group Oxford Limited, Oxford, UK.

Bouyer, J., Pruvot, M., Bengaly, Z., Guerin, P.M., Lancelot, R., 2007. Learning influences host choice in tsetse. Biology Letters 3, 113-116.

Burnett, G.F., 1957. The relation between age and cold resistance in tsetse flies and the value of chilling when transporting tsetse for experiments. Proceedings of the Royal Entomological Society of London A 32, 53-58.

Bursell, E., 1959. The water balance of tsetse flies. Transactions of the Royal Entomological Society of London 111, 205-235.

Bursell, E., 1960. The effect of temperature on the consumption of fat during pupal development in Glossina. Bulletin of Entomological Research 51, 583-598.

Bursell, E., 1964. Environmental aspects: temperature. In: Rockstein, M. (Ed.), The Physiology of Insecta. Academic Press, New York, pp. 283-321.

Bursell, E., Taylor, P., 1980. An energy budget for Glossina (Diptera: Glossinidae). Bulletin of Entomological Research 70, 187-196.

Buxton, P.A., Lewis, D.J., 1934. Climate and tsetse flies: laboratory studies upon Glossina submorsitans and tachinoides. Philosophical Transactions of the Royal Society of London B 224, 175-242.

Cattand, P., Desjeux, P., Guzmán, M.G., Jannin, J., Kroeger, A., Médici, A., Musgrove, P., Nathan, M.B., Shaw, A., Schofield, C.J., 2006. Tropical diseases lacking adequate control measures: dengue, leishmaniasis, and African trypanosomiasis. In: Jamison, D.T., et al. (Eds.), Disease Control Priorities in Developing Countries, second ed. Oxford University Press, New York, pp. 451-466.

Chown, S.L., Nicolson, S.W., 2004. Insect Physiological Ecology. Mechanisms and Patterns. Oxford University Press, Oxford.

Chown, S.L., Terblanche, J.S., 2007. Physiological diversity in insects: ecological and evolutionary contexts. Advances in Insect Physiology $33,50-152$.

Colinet, H., Hance, T., Vernon, P., 2006. Water relations, fat reserves, survival, and longevity of a cold-exposed parasitic wasp Aphidius colemani (Hymenoptera: Aphidiinae). Environmental Entomology 35, 228-236.

David, R.J., Gibert, P., Pla, E., Petavy, G., Karan, D., Moreteau, B., 1998. Cold stress tolerance in Drosophila: analysis of chill coma recovery in D. melanogaster. Journal of Thermal Biology 23, 291-299.

David, J.R., Gibert, P., Moreteau, B., Gilchrist, G.W., Huey, R.B., 2003. The fly that came in from the cold: geographic variation in recovery time from low-temperature exposure in Drosophila subobscura. Functional Ecology 17, 425-430. 
Esterhuizen, J., Kappmeier Green, K., Marcotty, T., van den Bossche, P., 2005. Abundance and distribution of the tsetse flies, Glossina austeni and G. brevipalpis, in different habitats in South Africa. Medical and Veterinary Entomology 19, 367-371.

FAO/IAEA, 2002. Annual Report. FAO/IAEA Entomology Unit, Agriculture and Biotechnology Laboratory, Seibersdorf, Austria.

Gaston, K.J., 2003. The Structure and Dynamics of Geographic Ranges. Oxford University Press, Oxford.

Gibert, P., Moreteau, B., Petavy, G., Karan, D., David, J.R., 2001. Chillcoma tolerance, a major climatic adaptation among Drosophila species. Evolution 55, 1063-1068.

Githeko, A.K., Lindsay, S.W., Confalonieri, U.E., Patz, J.A., 2000. Climate change and vector-borne diseases: a regional analysis. Bulletin of the World Health Organisation 78, 1136-1147.

Graham, C.H., Hijmans, R.J., 2006. A comparison of methods for mapping species ranges and species richness. Global Ecology and Biogeography 15, 578-587.

Hargrove, J.W., 2001. The effect of temperature and saturation deficit on mortality in populations of male Glossina $m$. morsitans (Diptera: Glossinidae) in Zimbabwe and Tanzania. Bulletin of Entomological Research 91, 79-86.

Hargrove, J.W., 2004. Tsetse population dynamics. In: Maudlin, I., Holmes, P.H., Miles, M.A. (Eds.), The Trypanosomiases. CABI Publishing, Wallingford, pp. 113-138.

Hargrove, J.W., Brady, J., 1992. Activity rhythms of tsetse flies (Glossina spp.) (Diptera: Glossinidae) at low and high temperatures in nature. Bulletin of Entomological Research 82, 321-326.

Hargrove, J.W., Williams, B.G., 1998. Optimized simulation as an aid to modelling, with an application to the study of a population of tsetse flies, Glossina morsitans morsitans Westwood (Diptera: Glossinidae). Bulletin of Entomological Research 88, 425-435.

Harvell, C.D., Mitchell, C.E., Ward, J.R., Altizer, S., Dobson, A.P., Ostfeld, R.S., Samuel, M.D., 2002. Climate warning and disease risks for terrestrial and marine biota. Science 296, 2158-2162.

Hawes, T.C., Couldridge, C.E., Bale, J.S., Worland, M.R., Convey, P., 2006. Habitat temperature and the temporal scaling of cold hardening in the high Arctic collembolan, Hypogastrura tullbergi (Schäffer). Ecological Entomology 31, 450-459.

Helmuth, B., Harley, C.D.G., Halpin, P.M., O'Donnel, M., Hofmann, G.E., Blanchette, C.A., 2002. Climate change and latitudinal patterns of intertidal thermal stress. Science 298, 1015-1017.

Helmuth, B., Kingsolver, J.G., Carrington, E., 2005. Biophysics, physiological ecology, and climate change: does mechanism matter? Annual Review of Physiology 67, 177-201.

Hendrickx, G., Napala, A., Dao, B., Batawui, D., De Deken, R., Vermeilen, A., Slingenbergh, J.H.W., 1999. A systematic approach to area-wide tsetse distribution and abundance maps. Bulletin of Entomological Research 89, 231-244.

Hijmans, R.J., Graham, C.H., 2006. The ability of climate envelope models to predict the effect of climate change on species distributions. Global Change Biology 12, 2272-2281.

Hijmans, R.J., Cameron, S.E., Parra, J.L., Jones, P.G., Jarvis, A., 2005. Very high resolution interpolated climate surfaces for global land areas. International Journal of Climatology 25, 1965-1978.

Hoffmann, A.A., Hallas, R., Anderson, A.R., Telonis-Scott, M., 2005. Evidence for a robust sex-specific trade-off between cold resistance and starvation resistance in Drosophila melanogaster. Journal of Evolutionary Biology 18, 804-810.

Hulme, M., 1996. Climate Change and Southern Africa. An Exploration of Some Potential Impacts and Implications in the SADC Region. WWF International Climate Research Unit, Norwich.

Huyton, P.M., Brady, J., 1975. Some effects of light and heat on feeding and resting behavior of tsetse flies, Glossina morsitans Westwood. Journal of Entomology A-Physiology and Behaviour $50,23-30$.

Jack, R.W., 1942. The life economy of a tsetse fly. Proceedings of the Rhodesia Scientific Association 34, 2-15.
Jackson, C.H.N., 1954. The hunger-cycles of Glossina morsitans Westwood and G. swynnertoni Austen. Journal of Animal Ecology 23, $368-372$.

Kearney, M., Porter, W.P., 2004. Mapping the fundamental niche: physiology, climate and the distribution of a nocturnal lizard. Ecology 85, 3119-3131.

Kelty, J.D., Lee, R.E., 1999. Induction of rapid cold hardening by cooling at ecologically relevant rates in Drosophila melanogaster. Journal of Insect Physiology 45, 719-726.

Kerr, J.T., Kharouba, H.M., Currie, D.J., 2007. The macroecological contribution to global change solutions. Science 316, 1581-1584.

Kitron, U., Otieno, L.H., Hungerford, L.L., Odulaja, A., Brigham, W.U., Okello, O.O., Joselyn, M., Mohamed-Ahmed, M.M., Cook, E., 1996. Spatial analysis of the distribution of tsetse flies in the Lambwe Valley, Kenya using Landsat TM satellite imagery and GIS. Journal of Animal Ecology 65, 371-380.

Kovats, R.S., Campbell-Lendrum, D.H., McMichael, A.J., Woodward, A., Cox, J.St.H., 2001. Early effects of climate change: do they include changes in vector-borne disease? Philosophical Transactions of the Royal Society of London B 356, 1057-1068.

Kuhn, K.G., Campbell-Lendrum, D.H., Armstrong, B., Davies, C.R., 2003. Malaria in Britain: past, present, and future. Proceedings of the National Academy of Sciences of the USA 100, 9997-10001.

Langley, P.A., 1977. Physiology of tsetse flies (Glossina ssp.) (Diptera: Glossinidae): a review. Bulletin of Entomological Research 67, 523-574.

Leak, S.G.A., 1999. Tsetse Biology and Ecology. CABI Publishing, Wallingford.

Lee Jr., R.E., Chen, C.-P., Denlinger, D.L., 1987. A rapid cold-hardening process in insects. Science 238, 1415-1417.

Lee, R.E., Elnitsky, M.A., Rinehart, J.P., Hayward, S.A.L., Sandro, L.H., Denlinger, D.L., 2006. Rapid cold-hardening increases the freezing tolerance of the Antarctic midge Belgica antarctica. Journal of Experimental Biology 209, 399-406.

MacDonald, S.S., Rako, L., Batterham, P., Hoffmann, A.A., 2004. Dissecting chill coma recovery as a measure of cold resistance: evidence for a biphasic response in Drosophila melanogaster. Journal of Insect Physiology 50, 695-700.

Macfie, J.W.S., 1912. Experiments and observations upon Glossina palpalis. Bulletin of Entomological Research 3, 61-72.

Martens, P., Kovats, R.S., Nijhof, S., deVries, P., Livermore, M.T.J., Bradley, D.J., Cox, J., McMichael, A.J., 1999. Climate change and future populations at risk of malaria. Global Environmental Change 9, S89-S107.

Mellanby, K., 1936. Experimental work with the tsetse fly Glossina palpalis in Uganda. Bulletin of Entomological Research 27, 611-633.

Misener, S.R., Chen, C.-P., Walker, V.K., 2001. Cold tolerance and proline metabolic gene expression in Drosophila melanogaster. Journal of Insect Physiology 47, 393-400.

Mohamed-Ahmed, M.M., Wynholds, Y., 1997. Effects of vegetation and weather on trap catches of Glossina fuscipes fuscipes near Lake Victoria, Kenya. Entomologia Experimentalis et Applicata 85, 231-236.

Mutika, G.N., Opiyo, E., Robinson, A.S., 2001. Assessing mating performance of male Glossina pallidipes (Diptera: Glossinidae) using a walk-in field cage. Bulletin of Entomological Research 91, 281-287.

Muzari, M.O., Hargrove, J.W., 2005. Artificial larviposition sites for field collections of the puparia of tsetse flies Glossina pallidipes and G. m. morsitans (Diptera: Glossinidae). Bulletin of Entomological Research 95, 221-229.

Nilson, T.L., Sinclair, B.J., Roberts, S.P., 2006. The effects of carbon dioxide anesthesia and anoxia on rapid cold-hardening and chill coma recovery in Drosophila melanogaster. Journal of Insect Physiology 52, 1027-1033.

Parmesan, C., Yohe, G., 2003. A globally coherent fingerprint of climate change impacts across natural systems. Nature 421, 37-42.

Pascual, M., Ahumada, J.A., Chaves, L.F., Rodo, X., Bouma, M., 2006. Malaria resurgence in the East African highlands: temperature trends 
revisited. Proceedings of the National Academy of Sciences USA 103, $5829-5834$.

Patz, J.A., 2002. A human disease indicator for the effects of recent global climate change. Proceedings of the National Academy of Sciences USA 99, 12506-12508.

Patz, J.A., Graczyk, T.K., Geller, N., Vittor, A.Y., 2000. Effects of environmental change on emerging parasitic diseases. International Journal for Parasitology 30, 1395-1405.

Phelps, R.J., Burrows, P.M., 1969. Lethal temperature for puparia of Glossina morsitans orientalis. Entomologia Experimentalis et Applicata $22,23-32$.

Pörtner, H.O., Knust, R., 2007. Climate change affects marine fishes through oxygen limitation of thermal tolerance. Science 315, 95-97.

Potts, W.H., 1933. Observations on Glossina morsitans, Westw., in East Africa. Bulletin of Entomological Research 24, 293-300.

Purse, B.V., Mellor, P.S., Rogers, D.J., Samuel, A.R., Mertens, P.P.C., Baylis, M., 2005. Climate change and the recent emergence of bluetongue in Europe. Nature Reviews Microbiology 3, 171-181.

Rako, L., Hoffmann, A.A., 2006. Complexity of the cold acclimation response in Drosophila melanogaster. Journal of Insect Physiology 52, 94-104.

Robays, J., Kadima, A.E., Lutumba, P., Bilenge, C.M.M., Mesu, V.K.B.K., De Deken, R., Makabuza, J., Deguerry, M., Van der Stuyft, P., Boelaert, M., 2004. Human African trypanosomiasis amongst urban residents in Kinshasa: a case-control study. Tropical Medicine and International Health 9, 869-875.

Robinson, T., Rogers, D., Williams, B., 1997a. Mapping tsetse habitat suitability in the common fly belt of Southern Africa using multivariate analysis of climate and remotely sensed vegetation data. Medical and Veterinary Entomology 11, 235-245.

Robinson, T., Rogers, D., Williams, B., 1997b. Univariate analysis of tsetse habitat in the common fly belt of Southern Africa using climate and remotely sensed vegetation data. Medical and Veterinary Entomology 11, 223-234.

Rogers, D.J., 1990. A general model for tsetse populations. Insect Science and its Application 11, 331-346.

Rogers, D.J., 2000. Satellites, space, time and the African trypanosomiases. Advances in Parasitology 47, 129-171.

Rogers, D.J., 2006. Models for vectors and vector-borne diseases. Advances in Parasitology 62, 1-37.

Rogers, D.J., Packer, M.J., 1993. Vector-borne diseases, models, and global change. The Lancet 342, 1282-1284.

Rogers, D.J., Randolph, S.E., 1986. Distribution and abundance of tsetse flies (Glossina spp.). Journal of Animal Ecology 55, 1007-1025.

Rogers, D.J., Randolph, S.E., 1991. Mortality rates and population density of tsetse flies correlated with satellite imagery. Nature 351, 739-741.

Rogers, D.J., Randolph, S.E., 1993. Distribution of tsetse and ticks in Africa: past, present and future. Parasitology Today 9, 266-271.

Rogers, D.J., Randolph, S.E., 2000. The global spread of malaria in a future, warmer world. Science 289, 1763-1766.

Rogers, D.J., Randolph, S.E., 2002. A response to the aim of eradicating tsetse from Africa. Trends in Parasitology 18, 534-536.

Rogers, D.J., Randolph, S.E., 2006. Climate change and vector-borne diseases. Advances in Parasitology 62, 346-382.

Rogers, D.J., Robinson, T.P., 2004. Tsetse distribution. In: Maudlin, I., Holmes, P.H., Miles, M.A. (Eds.), The Trypanosomiases. CABI Publishing, Wallingford, pp. 139-180.

Rogers, D.J., Williams, B.G., 1994. Tsetse distribution in Africa: seeing the wood and the trees. In: Edwards, P.J., May, R.M., Webb, N.R. (Eds.), Large-Scale Ecology and Conservation Biology. Blackwell Science, Oxford, pp. 247-271.

Rogers, D.J., Randolph, S.E., Snow, R.W., Hay, S.I., 2002. Satellite imagery in the study and forecast of malaria. Nature 415, 710-715.

Roura-Pascual, N., Suarez, A.V., Gomez, C., Pons, P., Touyama, Y., Wild, A.L., Peterson, A.T., 2004. Geographical potential of Argentine ants (Linepithema humile Mayr) in the face of global climate change. Proceedings of the Royal Society of London B 271, 2527-2534.

Sinclair, B.J., Chown, S.L., 2003. Rapid responses to high temperature and desiccation but not to low temperature in the freeze-tolerant subAntarctic caterpillar Pringleophaga marioni (Lepidoptera, Tineidae). Journal of Insect Physiology 49, 45-52.

Sinclair, B.J., Chown, S.L., 2005. Deleterious effects of repeated cold exposure in a freeze-tolerant sub-Antarctic caterpillar. Journal of Experimental Biology 208, 869-879.

Sinclair, B.J., Chown, S.L., 2006. Rapid cold-hardening in a Karoo beetle, Afrinus sp. Physiological Entomology 31, 98-101.

Sinclair, B.J., Terblanche, J.S., Scott, M.B., Blatch, G.L., Klok, C.J., Chown, S.L., 2006. Environmental physiology of three species of Collembola at Cape Hallett, North Victoria Land, Antarctica. Journal of Insect Physiology 52, 29-50.

Sumilo, D., Asokliene, L., Bormane, A., Vasilenko, V., Golovljova, I., Randolph, S.E., 2007. Climate change cannot explain the upsurge of tick-borne encephalitis in the Baltics. PLoS One 6, e500.

Sutherst, R.W., 2004. Global change and human vulnerability to vectorborne diseases. Clinical Microbiology Reviews 17, 136-173.

Terblanche, J.S., Chown, S.L., 2006. The relative contributions of developmental plasticity and adult acclimation to physiological variation in the tsetse fly, Glossina pallidipes (Diptera, Glossinidae). Journal of Experimental Biology 209, 1064-1073.

Terblanche, J.S., Chown, S.L., 2007. The effects of temperature, body mass and feeding on metabolic rate in the tsetse fly Glossina morsitans centralis. Physiological Entomology 32, 175-180.

Terblanche, J.S., Klok, C.J., Chown, S.L., 2005. Temperature-dependence of metabolic rate in Glossina morsitans morsitans (Diptera, Glossinidae) does not vary with gender, age, feeding, pregnancy or acclimation. Journal of Insect Physiology 51, 861-870.

Terblanche, J.S., Klok, C.J., Krafsur, E.S., Chown, S.L., 2006. Phenotypic flexibility and geographic variation in thermal tolerance and water loss of the tsetse fly Glossina pallidipes (Diptera: Glossinidae): implications for distribution modelling. American Journal of Tropical Medicine and Hygiene 74, 786-794.

Terblanche, J.S., Marais, E., Chown, S.L., 2007. Stage-related variation in rapid cold hardening as a test of the environmental predictability hypothesis. Journal of Insect Physiology 53, 455-462.

Terblanche, J.S., Deere, J.A., Clusella Trullas, S., Janion, C., Chown, S.L. Critical thermal limits are context dependent. Proceedings of the Royal Society of London B, in press, doi:10.1098/rspb.2007.0985.

Thomas, C.D., Cameron, A., Green, R.E., Bakkenes, M., Beaumont, L.J., Collingham, Y.C., et al., 2004. Extinction risk from climate change. Nature 427, 145-148.

Thuiller, W., Lavorel, S., Araujo, M.B., Sykes, M.T., Prentice, I.C., 2005. Climate change threats to plant diversity in Europe. Proceedings of the National Academy of Sciences USA 102, 8245-8250.

Torr, S.J., Hargrove, J.W., 1999. Behaviour of tsetse (Diptera: Glossinidae) during the hot season in Zimbabwe: the interaction of microclimate and reproductive status. Bulletin of Entomological Research 89, 365-379.

Urban, M.C., Phillips, B.L., Skelly, D.K., Shine, R., 2007. The cane toad's (Chaunus $[$ Bufo] marinus) increasing ability to invade Australia is revealed by a dynamically updated range model. Proceedings of the Royal Society of London B 274, 1413-1419.

Van Etten, J., 1982. Comparative studies on the diurnal activity pattern in two field and laboratory populations of Glossina pallidipes. Entomologia Experimentalis et Applicata 32, 38-45.

Walther, G.-R., Post, E., Convey, P., Menzel, A., Parmesan, C., Beebee, T.J.C., Fromentin, J.-M., Hoegh-Guldberg, O., Bairlein, F., 2002. Ecological responses to recent climate change. Nature 416, 389-395.

Wilson, R.J., Gutiérrez, D., Gutiérrez, J., Martínez, D., Agudo, R., Monserrat, V.J., 2005. Changes to the elevational limits and extent of species ranges associated with climate change. Ecology Letters 8, $1138-1146$. 